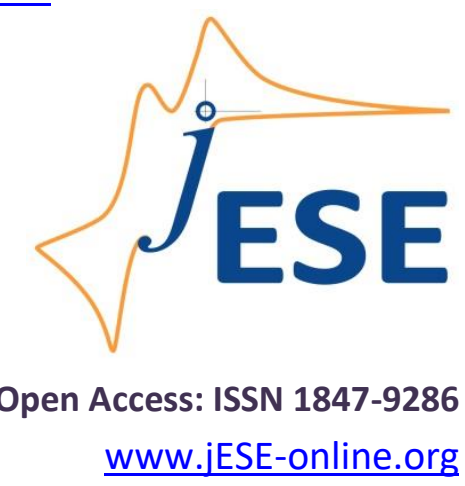

Review

\title{
Influence of the exchange current density and overpotential for hydrogen evolution reaction on the shape of electrolytically produced disperse forms
}

\author{
Nebojša D. Nikolić \\ ICTM-Department of Electrochemistry, University of Belgrade, Njegoševa 12, P.O.B. 473, Belgrade, \\ Serbia
}

区nnikolic@ihtm.bg.ac.rs; Tel.: +381 1133703 90; Fax: +381 113370389

Received: July 4, 2019; Revised: August 14, 2019; Accepted: August 14, 2019

\begin{abstract}
In this study, comprehensive survey of formation of disperse forms by the electrolysis from aqueous electrolytes and molten salt electrolysis has been presented. The shape of electrolitically formed disperse forms primarily depends on the nature of metals, determined by the exchange current density (jo) and overpotential for hydrogen evolution reaction as a parallel reaction to metal electrolysis. The decrease of the jo value leads to a change of shape of dendrites from the needle-like and the 2D fern-like dendrites (metals characterized by high jo values) to the 3D pine-like dendrites (metals characterized by medium jo values). The appearing of a strong hydrogen evolution leads to formation of cauliflower-like and spongy-like forms (metals characterized by medium and low jovalues). The other disperse forms, such as regular and irregular crystals, granules, cobweb-like, filaments, mossy and boulders, usually feature metals characterized by the high jo values. The globules and the carrot-like forms are a characteristic of metals with the medium jo values. The very long needles were a product of molten salt electrolysis of magnesium nitrate hexahydrate. Depending on the shape of the disperse forms, i.e. whether they are formed without and with vigorous hydrogen evolution, formation of all disperse forms can be explained by either application of the general theory of disperse deposits formation or the concept of "effective overpotential". With the decrease of jo value, the preferred orientation of the disperse forms changed from the strong (111) in the needle-like and the fern-like dendrites to randomly oriented crystallites in the 3D pine-like dendrites and the cauliflower-like and the spongy-like forms.
\end{abstract}

\section{Keywords}

Electrolysis; metal; morphology; powder particles; SEM. 


\section{Basic facts}

The disperse (powder, irregular) forms of metal deposits can be obtained by electrolysis from aqueous electrolytes and molten salt electrolysis [1,2]. The typical disperse forms obtained by electrolysis are: dendrites of different shape, crystals of regular and irregular shape, cobweb, needles, wires, carrot, globules, granules, cauliflower, the honeycomb, spongy, mossy, filaments, etc. The shape of disperse forms depends on the regimes and parameters of electrolysis, and the nature of metals. The both constant (potentiostatic and galvanostatic) and periodically changing (pulsating overpotential (PO), pulsating current (PC) and reversing current (RC)) regimes of electrolysis are used for production of disperse forms. The main parameters affecting the shape of disperse forms are: the type and composition of electrolytes, temperature of electrolysis, the type of cathode, stirring of electrolyte, the addition of specific substances known as additives, etc.

According to the exchange current density, melting point and overpotential for hydrogen evolution reaction, metals are classified into three classes [3]:

a) Class I, so-called normal metals like silver, cadmium, lead, tin and zinc. This group of metals is characterized by the high values of both the exchange current density $\left(j_{0}>1 \mathrm{~A} \mathrm{dm}^{-2} ; j_{0}\right.$ is the exchange current density) and overpotential for hydrogen evolution reaction, and low melting point,

b) Class II, so-called intermediate metals like copper, gold and silver (ammonium electrolyte). This group of metals is characterized by moderate melting points, the medium exchange current density values $\left(10^{-2}<j_{0}<1 \mathrm{~A} \mathrm{dm}^{-2}\right)$, and the lower values of overpotential for hydrogen evolution than the normal metals, and

c) Class III, so-called inert metals like nickel, cobalt, iron and platinum. This group of metals is characterized by the low values of the both exchange current density $\left(10^{-2}>j_{0}>10^{-12} \mathrm{~A} \mathrm{dm}^{-2}\right)$ and overpotential for hydrogen evolution reaction, and high melting points.

A schematic illustration of position of the typical metals from each of these groups on the scale of the exchange current density is shown in Fig. 1. The values of their exchange current densities are summarized in Table 1.

\section{$\stackrel{\text { decreasing } j_{0}}{\longrightarrow}$}

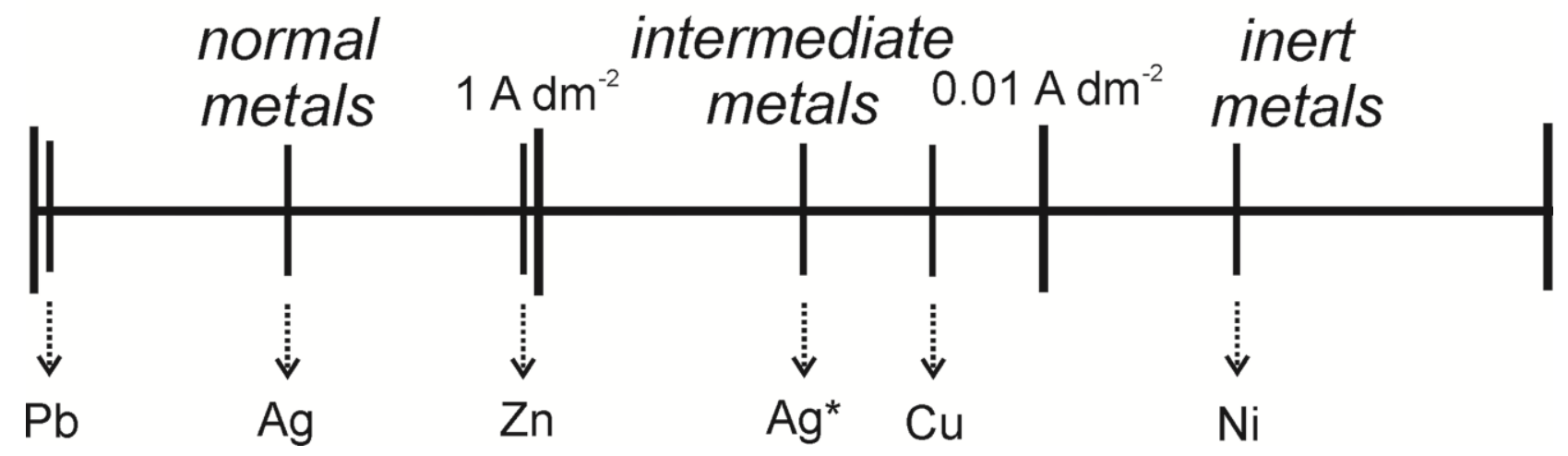

Figure 1. A schematic position of metals on a scale of the exchange current density values

( $A g^{*}$ - the ammonium electrolyte)

This mini Author's review gives a comprehensive survey of morphological characteristics of disperse forms of lead, silver and zinc (the normal metals), copper and silver (the intermediate metals) and nickel (the inert metal). 
Table 1. The values of the exchange current density for some technologically important metals

\begin{tabular}{cccc}
\hline Class of metals & $\begin{array}{c}\text { The kind } \\
\text { of metals }\end{array}$ & $\begin{array}{c}\text { The exchange current } \\
\text { density, } j_{0} / \mathrm{A} \mathrm{dm}^{-2}\end{array}$ & Reference: \\
\hline Normal metals & $\mathrm{Pb}$ & $j_{0} \rightarrow \infty$ & {$[4]$} \\
\hline & $\mathrm{Ag}$ & $100-700$ & {$[5]$} \\
\hline Intermediate & $\mathrm{Ag}$ (ammonium electrolyte) & $1.84-8.8 ; 0.8-37$ & {$[6,7]$} \\
\hline metals & $\mathrm{Cu}$ & 0.025 & {$[8]$} \\
\hline Inert metals & $\mathrm{Ni}$ & $0.011-0.032$ & {$[1,9]$} \\
\hline
\end{tabular}

\section{Class I, so-called normal metals}

The common characteristic of this group of metals is formation of disperse (powder, irregular) forms starting from small overpotentials, and the absence of formation of compact deposits without use of additives [1,2]. There is no unique and precise way for determination of the exchange current density values of this group of metals, and auxiliary ways are proposed for their estimation [4,6,7].

Lead

The processes of lead electrodeposition belong to the very fast electrochemical processes, and the estimated values of the exchange current density for $\mathrm{Pb}$ tend to infinity [4]. Pb electrodeposition occurs in the conditions of the mixed ohmic-diffusion control $[2,10]$. The ohmic control is defined by a straight-line dependence of current on overpotential. The ratio of the ohmic control to the overall control of the electrodeposition increases with increasing concentration of $\mathrm{Pb}(\mathrm{II})$ ions [10], and decreasing concentration of the supporting electrolyte $\left(\mathrm{NaNO}_{3}\right)$ [11] (Fig. 2). The inflection point at the polarization curve denotes the end of the plateau of the limiting diffusion current, and the fast growth of the current density with the increase of overpotential after the inflection point is observed (Fig. 2).

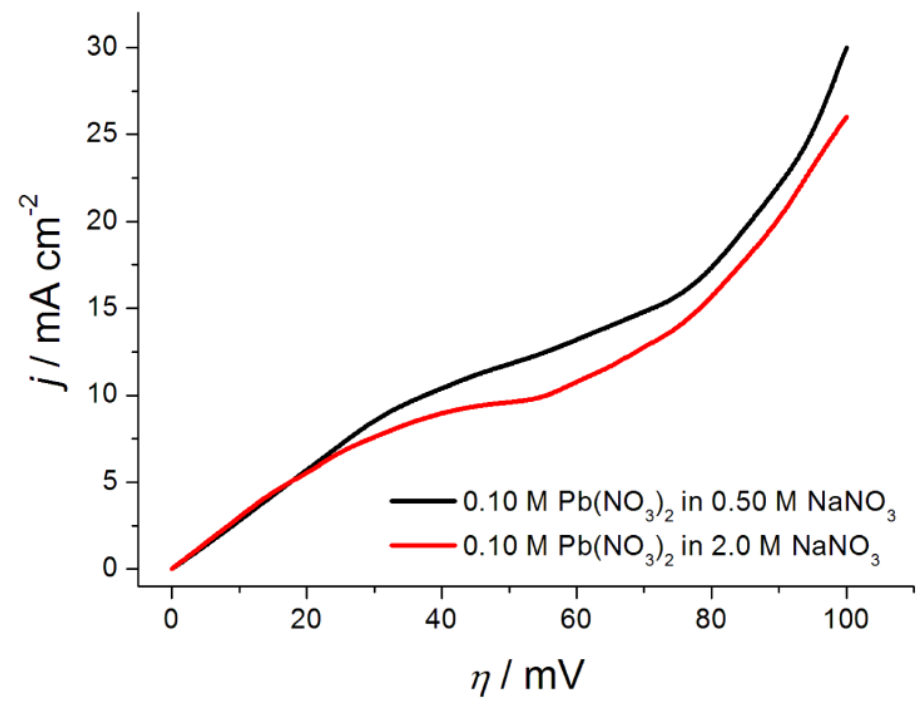

Figure 2. Polarization curves for Pb electrodeposition from $0.10 \mathrm{M} \mathrm{Pb}\left(\mathrm{NO}_{3}\right)_{2}$ in 0.50 and $2.0 \mathrm{M} \mathrm{NaNO}_{3}$.

Figure 3 shows a typical disperse forms obtained under the different electrodeposition conditions. The regular hexagonal crystals are a characteristic of the ohmic control (Fig. 3a). ${ }^{*}$ The mixture of needle-like dendrites and crystals of irregular shape is obtained by electrodeposition at the

\footnotetext{
* The exact experimental conditions for formation of this form, as well as all others forms shown in this study are given in the corresponding references indicated in Figure captions.
} 
overpotential belonging to the plateau of the limiting diffusion current density (Fig. 3b). Finally, the two-dimensional (2D) fern-like dendrites are formed by electrodeposition outside the plateau of the limiting diffusion current density in the zone of the fast increase in the current density with increasing overpotential after the inflection point (Fig. 3c). Depending on a concentration either $\mathrm{Pb}(\mathrm{II})$ ions or $\mathrm{NaNO}_{3}$, the very long needle-like dendrites can be formed (Fig. 3d).

The shape of regular hexagonal crystals does not depend on the type of electrolyte $[12,13]$. On the other hand, the shape of dendrites strongly depends on the type of electrolyte, and for example, dendrites formed from the complex electrolytes like acetate [12] and hydroxide [13] (Fig. 3e) were more branchy structure than those obtained from the basic (nitrate) electrolyte (Fig. 3c) [14]. Following Wranglen's definition of a dendrite [15], dendrites obtained from the complex electrolytes usually belong to secondary $(\mathrm{S})$ and tertiary $(\mathrm{T})$ types, while those obtained from the nitrate electrolyte belong to primary (P) type [14]. According to Wranglen [15], a dendrite is a skeleton of a monocrystal and consists of a stalk and branches, thereby resembling a tree. The dendrite consisted only of the stalk and primary branches is referred as primary $(P)$ dendrite. If the primary branches in turn develop secondary branches, the dendrite is called secondary (S). The two-dimensional (2D) dendrite refers to dendrites with branches that lie in the same plane as that of the primary stalk [16]. The branches developed from the secondary branches are known as tertiary $(T)$ ones, etc.

Aside from dendrites of different shape and regular and irregular crystals, the granules (Fig. $3 f$ and $\mathrm{g}$ ) and the cobweb-like particles (Fig. 3h) were also formed by Pb electrodeposition. These particles are usually formed by $\mathrm{Pb}$ electrodeposition from electrolytes with the low concentrations of $\mathrm{Pb}(\mathrm{II})$ ions $[17,18]$.

Irrespective of the type of electrolyte, the X-ray diffraction (XRD) analysis showed the predominant presence of $\mathrm{Pb}$ crystallites oriented in the (111) plane in all types of $\mathrm{Pb}$ particles $[13,19,20]$. This predominant presence of the crystallites oriented in the (111) plane can be attributed to the lower surface energy of this plane in relation to the other planes like (110) and (100) [21,22], where the values of the surface energy follow trend: $\gamma_{111}<\gamma_{100}<\gamma_{110}$, and $\gamma$ is the surface energy. $\mathrm{Pb}$ crystallites were only oriented in the (111) plane in the regular hexagonal particles formed in the ohmic control, indicating that this particle type represents monocrystal of the (111) preferred orientation [19]. On the other hand, aside from $\mathrm{Pb}$ crystallites oriented in the (111) plane, the presence of $\mathrm{Pb}$ crystallites oriented in the other planes was observed in all types of dendritic particles, that can be considered as follows: due to different surface energy of crystal planes, electrodeposition rate on them are different, and for the fcc crystal lattice, follows a trend: $(110)>(110)>(111)$ [23]. The (111) plane belongs to a slow-growing plane, and in the growth process, this plane survives [19]. $\mathrm{Pb}$ crystallites oriented in this plane originate from growth centers present in the interior of crystals ("growth centre"). The other planes, such as (110) and (100), belong to the fast-growing planes, and in the growth process, these planes disappear. Pb crystallites oriented in these planes originate from the growth centers present on the tips, corners and edges ("tip", "edge" and "corner" types). In this way, the presence of Pb crystallites oriented in these planes is obvious.

\section{Silver}

The polarization curve for silver electrodeposition from the nitrate electrolyte $\left(0.10 \mathrm{M} \mathrm{AgNO}_{3}\right.$ in 2.0 $\mathrm{M} \mathrm{NaNO}_{3}$ ) shows a relatively short plateau of the limiting diffusion current density in the range of overpotentials between 70 and $110 \mathrm{mV}$ (Fig. 4) [24,25]. 
(a)

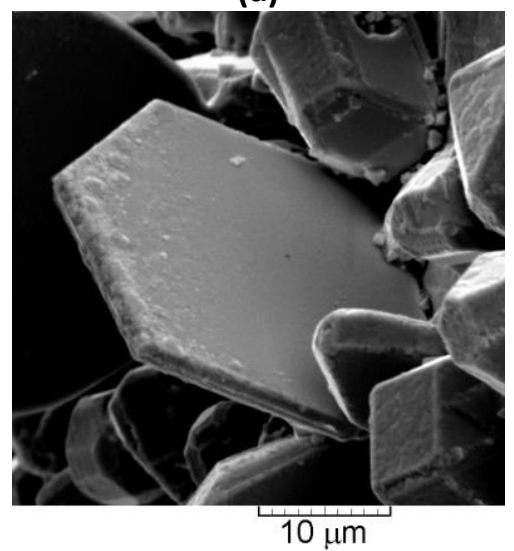

(d)

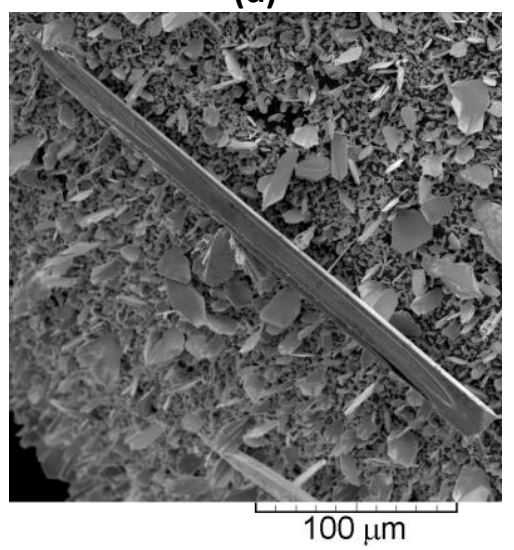

(g)

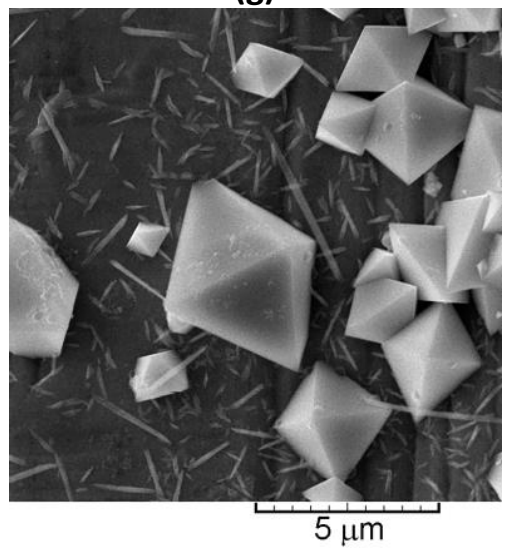

(b)

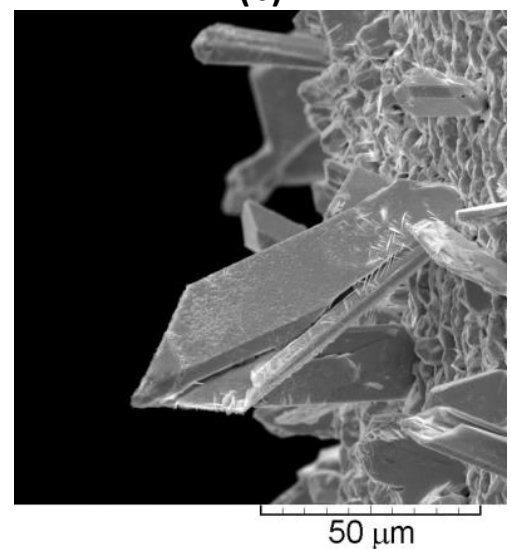

(e)

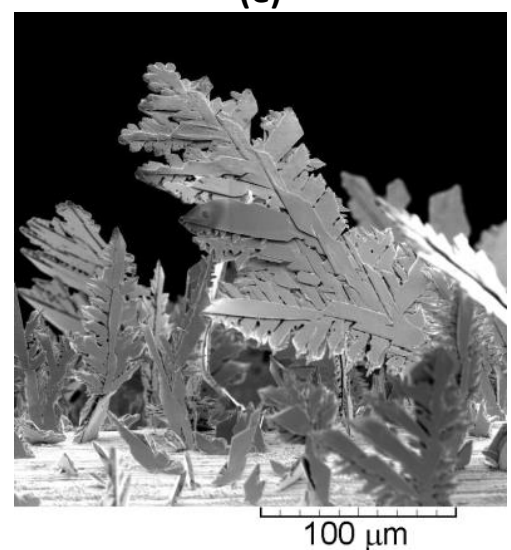

(h)

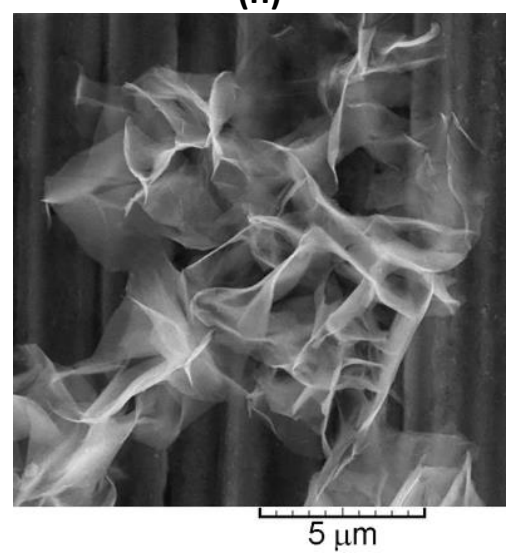

(c)

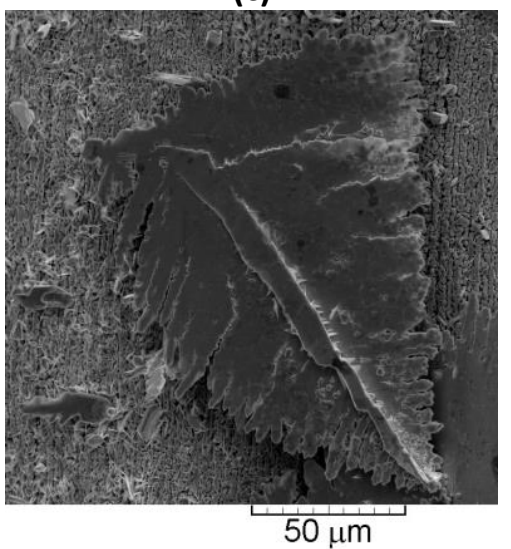

(f)

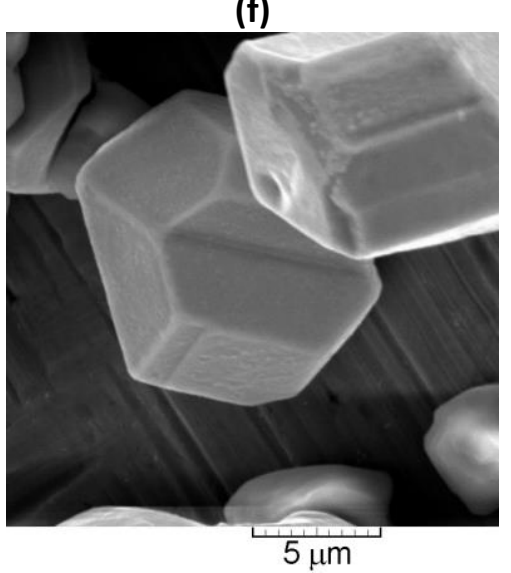

Figure 3. The typical disperse forms obtained by Pb electrodeposition from $0.10 \mathrm{M} \mathrm{Pb}\left(\mathrm{NO}_{3}\right)_{2}$ in $0.50 \mathrm{M}$ $\mathrm{NaNO}_{3}$ : (a) the regular hexagonal crystal $(\eta=20 \mathrm{mV})$ [11], (b) the irregular crystals ( $\left.\eta=50 \mathrm{mV}\right)$ [11], (c) the fern-like dendrite $(\eta=80 \mathrm{mV})[11]$, (d) the needle-like dendrite $\left(0.10 \mathrm{M} \mathrm{Pb}\left(\mathrm{NO}_{3}\right)_{2}\right.$ in $4.0 \mathrm{M} \mathrm{NaNO} \mathrm{N}_{3} ; \eta=$ $50 \mathrm{mV})$ [11], (e) the very branchy $2 \mathrm{D}$ dendrite $\left(0.10 \mathrm{M} \mathrm{Pb}\left(\mathrm{NO}_{3}\right)_{2}\right.$ in $\left.2.0 \mathrm{M} \mathrm{NaOH} ; \eta=80 \mathrm{mV}\right)$ [13],

(f) and (g) granules $\left(0.020 \mathrm{M} \mathrm{Pb}\left(\mathrm{NO}_{3}\right)_{2}\right.$ in $\left.2.0 \mathrm{M} \mathrm{NaNO}_{3} ; \eta=5 \mathrm{mV}\right)$ [17], h) cobweb-like particles $(0.010 \mathrm{M}$ $\mathrm{Pb}\left(\mathrm{NO}_{3}\right)_{2}$ in $\left.2.0 \mathrm{M} \mathrm{NaNO}_{3} ; \eta=62.5 \mathrm{mV}\right)$ [18]

Morphological analysis of deposits of $\mathrm{Ag}$ obtained at different overpotentials showed that granules were formed at the low overpotential (Fig. 5a), the mixture of the needle-like dendrites and granules was formed at the overpotential inside the plateau of the limiting diffusion current density (Fig. 5b), while the 2D fern-like dendrites were formed at the overpotential outside the plateau of the limiting diffusion current density in the zone of the fast increase in the current density with increasing overpotential after the inflection point (Fig. 5c). 


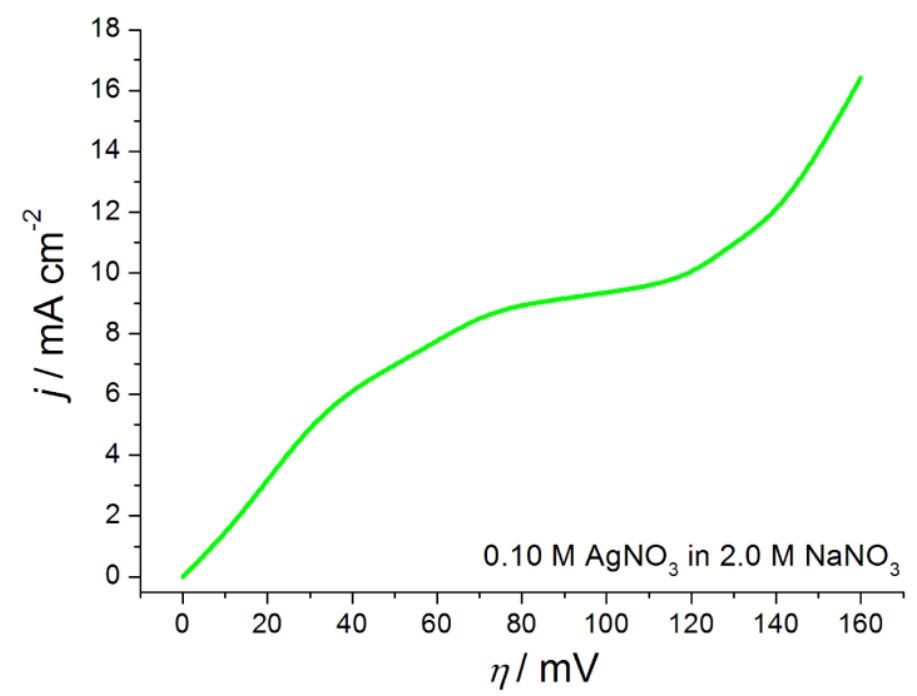

Figure 4. The polarization curve for silver electrodeposition from $0.10 \mathrm{M} \mathrm{AgNO}_{3}$ in $2.0 \mathrm{M} \mathrm{NaNO}_{3}$.

(a)

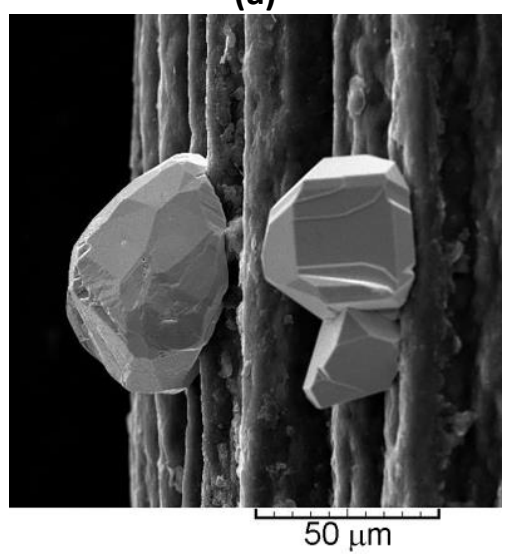

(b)

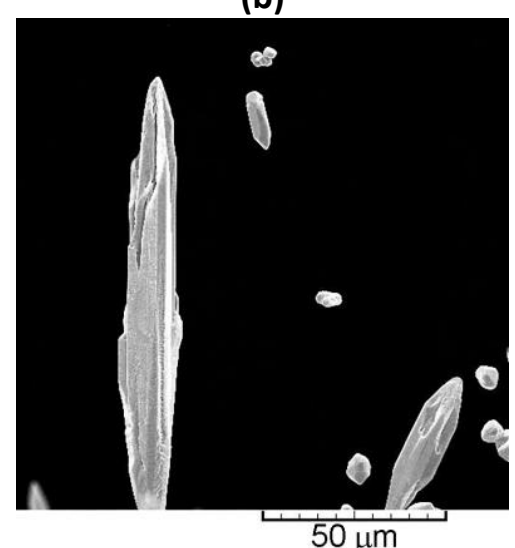

(c)

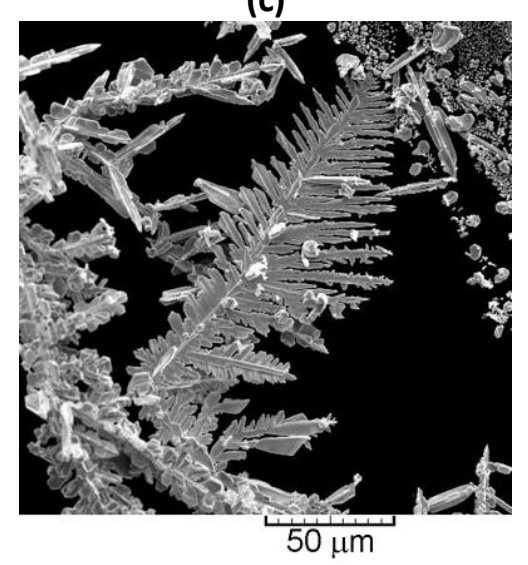

Figure 5. The disperse forms of $\mathrm{Ag}$ obtained by electrodeposition from $0.10 \mathrm{M} \mathrm{AgNO}_{3}$ in $2.0 \mathrm{M} \mathrm{NaNO}_{3}$ : (a) granules $(\eta=15 \mathrm{mV})$, (b) the mixture of the needle-like dendrites and granules $(\eta=90 \mathrm{mV})$, and (c) the 2D fern-like dendrite $(\eta=150 \mathrm{mV})$ [24].

The needle-like dendrites showed the strong (111) preferred orientation [24]. The strong (111) preferred orientation was also characteristic of the 2D fern-like dendrites, but with the larger ratio of Ag crystallites oriented in (220), (200) and (311) planes than in the needle-like dendrites.

Zinc

Unlike lead and silver, the typical polarization curve for zinc electrodeposition from an alkaline electrolyte showed the well defined plateau of the limiting diffusion current density, in the range of overpotentials between 110 and $180 \mathrm{mV}$ [6] (Fig. 6).

The filaments (Fig. 7a), grouped into mossy or spongy-like particles (Fig. 7b), are formed at the low overpotential. The large grains, referred as boulders, are formed at the overpotential close to the plateau of the limiting diffusion current density (Fig. 7c). The 2D fern-like dendrites and irregular crystals are formed by electrodeposition at the overpotential inside the plateau of the limiting diffusion current density (Fig. 7d). Finally, the very branchy 2D fern-like dendrites are formed at the overpotential outside the plateau of the limiting diffusion current density in the zone of the fast increase in the current density with increasing overpotential after the inflection point at the polarization curve (Fig. 7e and f). It is necessary to note formation of some positions at the electrode surface that are result of appearing of hydrogen evolution reaction as a parallel reaction to $\mathrm{Zn}$ electrolysis at the high overpotentials (Fig. 7e). 


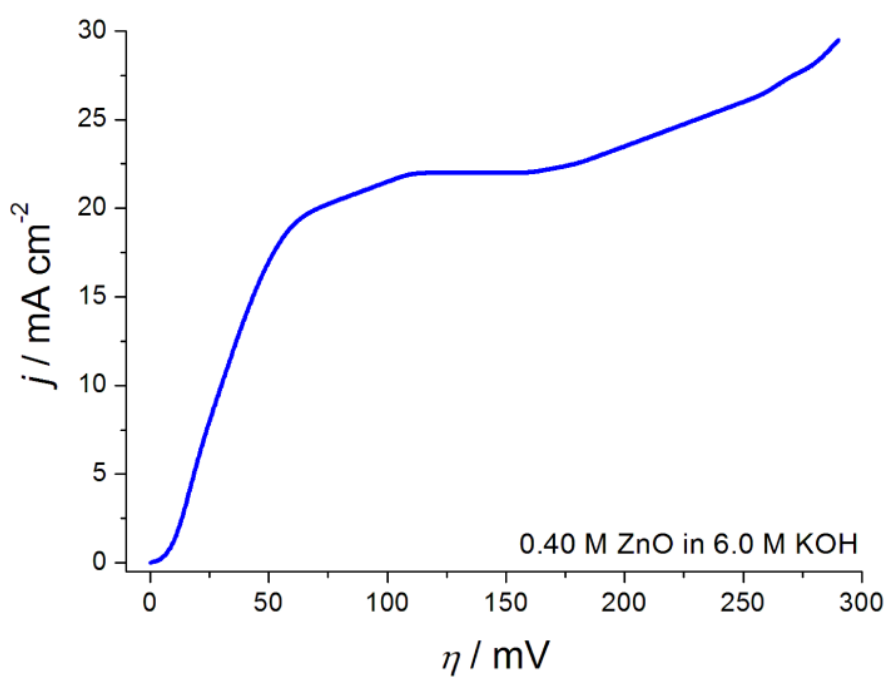

Figure 6. The polarization curve for Zn electrodeposition from $0.40 \mathrm{M} \mathrm{ZnO}$ in $6.0 \mathrm{M} \mathrm{KOH}$.

(a)

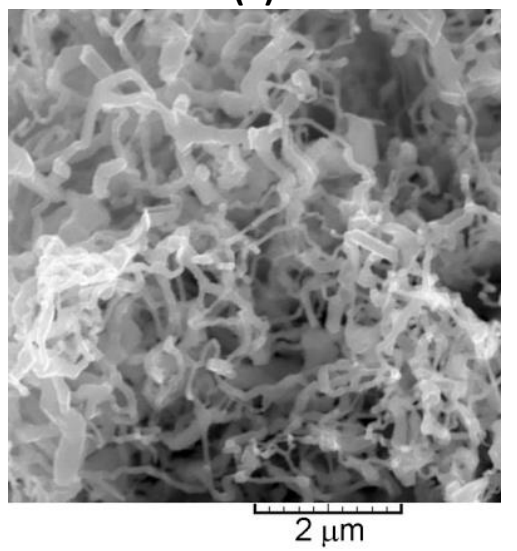

(d)

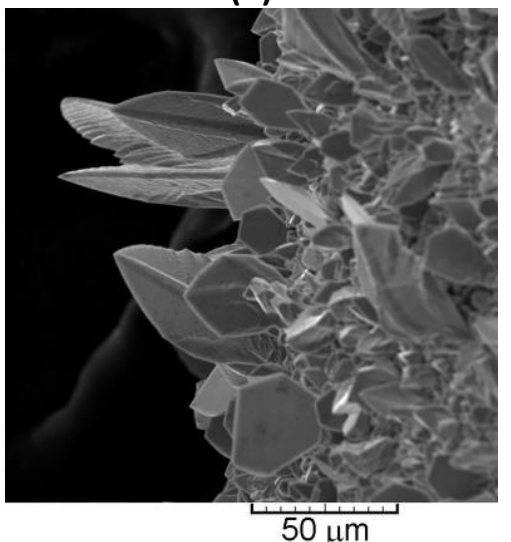

(b)

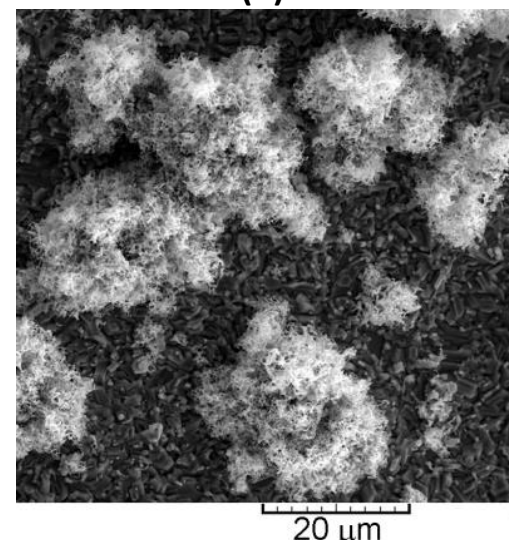

(e)

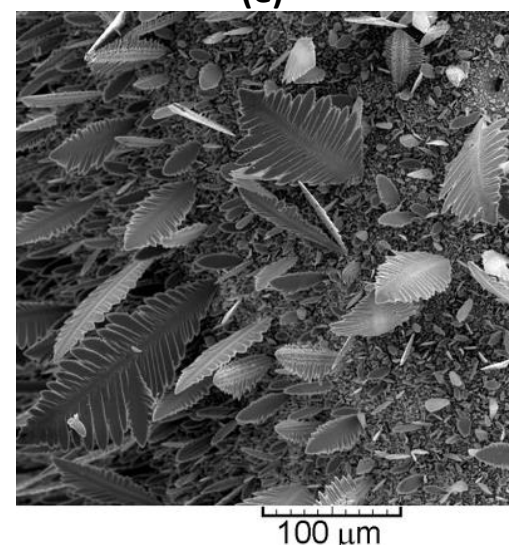

(c)

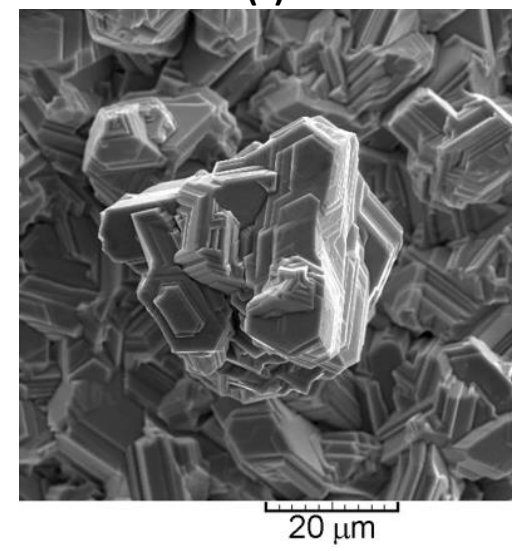

(f)

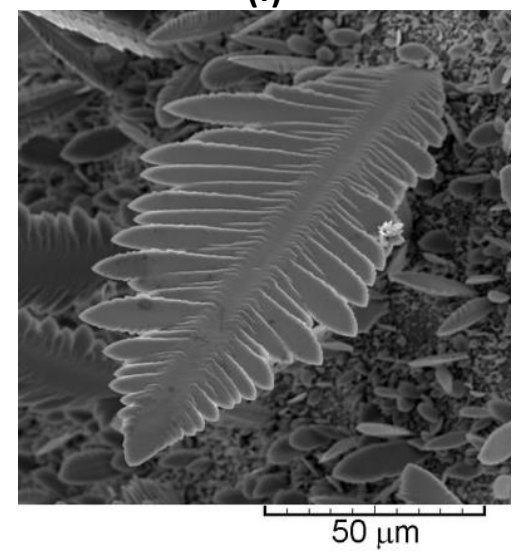

Figure 7. The disperse forms of $\mathrm{Zn}$ obtained by electrodeposition from $0.40 \mathrm{M} \mathrm{ZnO}$ in $6.0 \mathrm{M} \mathrm{KOH:} \mathrm{(a)}$ filaments $(\eta=25 \mathrm{mV})$, (b) mossy $(\eta=25 \mathrm{mV})$, (c) large grains or boulders $(\eta=65 \mathrm{mV})$, (d) the mixture of the $2 D$ dendrites and irregular crystals $(\eta=150 \mathrm{mV}),(e)$ and $(f)$ the $2 D$ fern-like dendrites $(\eta=225 \mathrm{mV})[6]$.

\section{The intermediate metals}

The disperse forms of metals from this group are formed in the activation-diffusion and diffusion controls of electrodeposition, as well as in the hydrogen co-deposition range (for copper) [2]. 


\section{Silver (ammonium electrolyte)}

The polarization curve for silver electrodeposition from the ammonium electrolyte shows the well defined plateau of the limiting diffusion current density, in the range of overpotentials between 250 and $700 \mathrm{mV}$ (Fig. 8) [26].

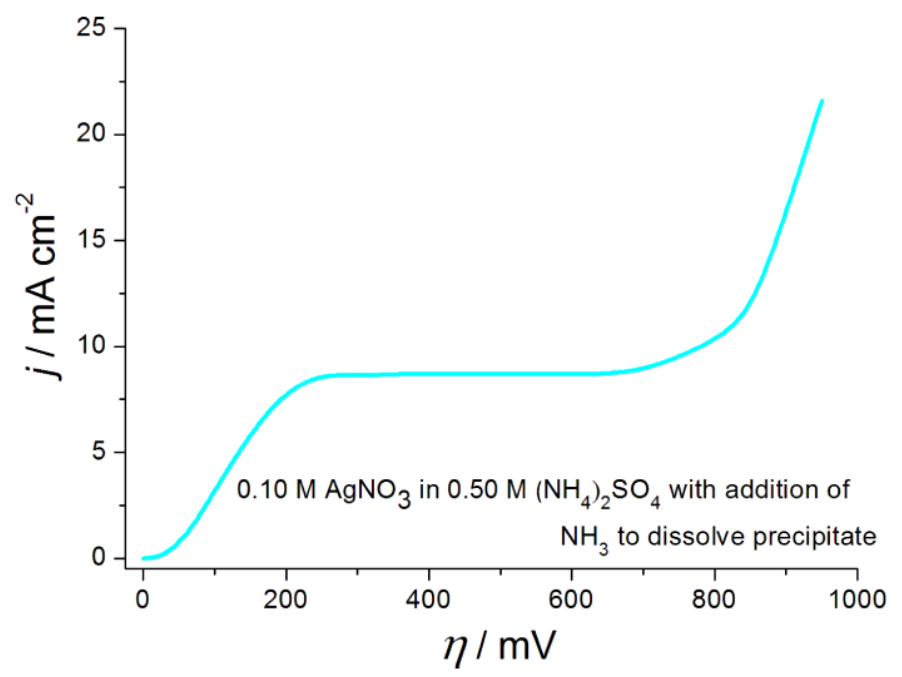

Figure 8. The polarization curve for $\mathrm{Ag}$ electrodeposition from $0.10 \mathrm{M} \mathrm{AgNO} \mathrm{O}_{3}$ in $0.50 \mathrm{M}\left(\mathrm{NH}_{4}\right)_{2} \mathrm{SO}_{4}$ with the addition of $\mathrm{NH}_{3}$ in excess to dissolve silver sulfate precipitate (ammonium electrolyte).

The three-dimensional (3D) pine-like dendrites constructed from the corncob-like forms as the basic element were formed by electrodeposition at the overpotential belonging to the plateau of the limiting diffusion current density ( $\eta=650 \mathrm{mV}$; Fig. 9a). The corncob-like forms consisted of small cauliflower-like agglomerates of approximately spherical grains [24]. The similar shape of the pinelike dendrites, but more branchy structure than those obtained by electrodeposition inside the plateau, was formed at the overpotential outside the plateau of the limiting diffusion current density ( $\eta=1000 \mathrm{mV}$; Fig. 9b).

(a)

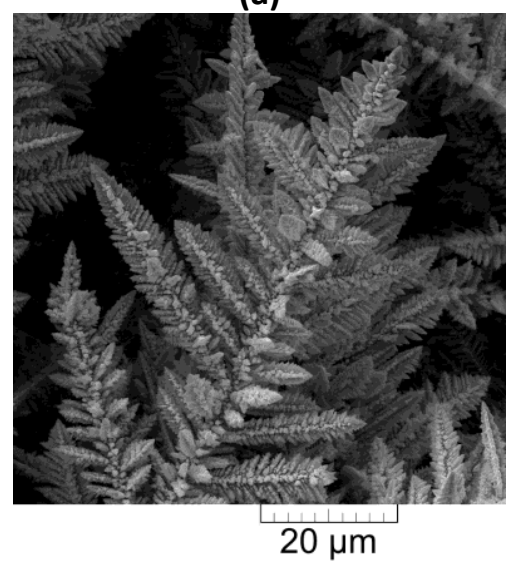

(b)

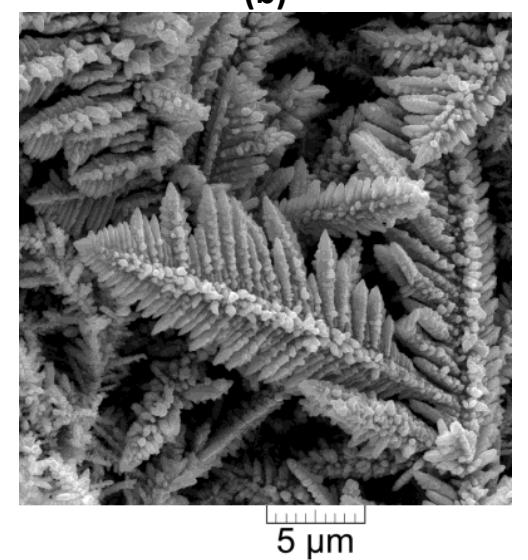

Figure 9. The $3 D$ pine-like dendrites formed by electrodeposition from the ammonium electrolyte at overpotentials of: (a) $650 \mathrm{mV}$, and (b) $1000 \mathrm{mV} \mathrm{[26].}$

The ratios of Ag crystallites oriented in (200), (220) and (311) planes increased with increasing overpotential of the electrodeposition, leading to almost randomly oriented $\mathrm{Ag}$ crystallites in the pine-like dendrites formed at the overpotential outside the plateau of the limiting diffusion current density [24]. 


\section{Copper}

The typical polarization curve for $\mathrm{Cu}$ electrodeposition shows a wide and the well defined the plateau of the limiting diffusion current density (Fig. 10). At the first sight, it is clear that the shape of this polarization curve was very similar to the one obtained for Ag from the ammonium electrolyte. The plateau of the limiting diffusion current density corresponds to the range of overpotentials between 300 and $750 \mathrm{mV}$ for solution containing $0.10 \mathrm{M} \mathrm{CuSO}_{4}$ in $0.50 \mathrm{M} \mathrm{H}_{2} \mathrm{SO}_{4}$, and no any difference in the length of the plateau of the limiting diffusion current density is observed with various concentrations of $\mathrm{H}_{2} \mathrm{SO}_{4}$ as the supporting electrolyte [27].

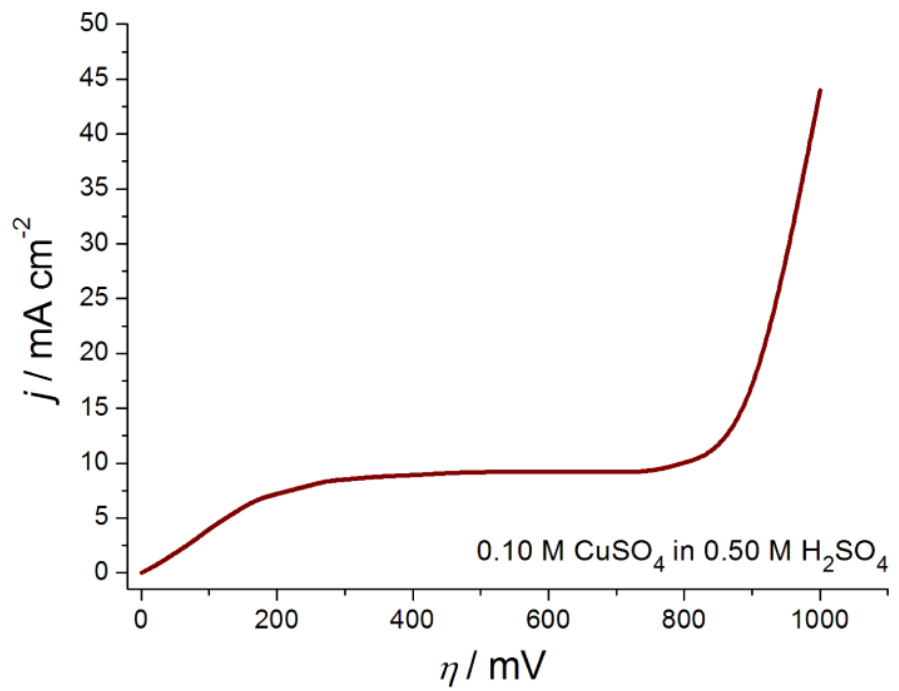

Figure 10. The polarization curve for Cu electrodeposition from $0.10 \mathrm{M} \mathrm{CuSO}_{4}$ in $0.50 \mathrm{M} \mathrm{H}_{2} \mathrm{SO}_{4}$.

The carrot-like forms, often with the sharp tips, (Fig. 11a) and globules (Fig. 11b) are formed in the mixed activation-diffusion control of the electrodeposition $[2,28]$. The cauliflower-like forms are formed at the beginning of the plateau of the limiting diffusion current density before the initiation of the dendritic growth (Fig. 11c).

The very branchy 3D pine-like dendrites constructed from the corncob-like forms as the basic element were formed at the overpotential belonging to the plateau of the limiting diffusion current density after an initiation of dendritic growth (Fig. 11d). The corncob-like forms were constructed from small cauliflower-like agglomerates of approximately spherical grains. Aside from the 3D pinelike dendrites, cauliflower-like agglomerates of $\mathrm{Cu}$ grains, and holes which origin is of detached hydrogen bubbles were also formed at an overpotential of $625 \mathrm{mV}$ which belonged to the plateau of the limiting diffusion current density (Fig. 11e).

The completely different situation was observed at the overpotential outside the plateau of the limiting diffusion current density. Dendritic growth was completely inhibited, and the honeycomblike structure was formed [2, 26] (Fig. 11f). The main characteristics of this structure type are holes formed by detached hydrogen bubbles and small agglomerates of approximately spherical grains formed around them. The absence of dendritic growth at an overpotential of $1000 \mathrm{mV}$ and the cauliflower-like character of the particles obtained after a removing the deposit from the honeycomb-like structure is clearly visible from Fig. $11 \mathrm{~g}$.

The honeycomb-like structures are formed in the conditions of vigorous hydrogen evolution reaction, where vigorous hydrogen evolution changes the hydrodynamic conditions in the nearelectrode layer leading to the decrease in the thickness of the diffusion layer of the macroelectrode, the increase in the limiting diffusion current density, and to the decrease of the degree of the 
diffusion control of the electrodeposition [29]. Formation of the cauliflower-like forms (Fig. 11g) instead of dendrites (Fig. 11d) really indicates the lower degree of the diffusion control at an overpotential of $1000 \mathrm{mV}$ than at $625 \mathrm{mV}$.

(a)

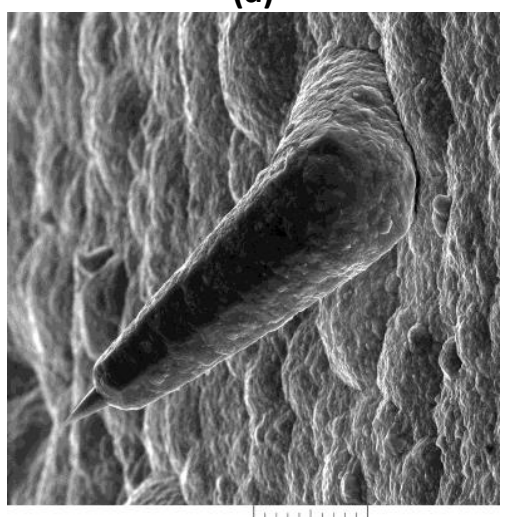

$10 \mu \mathrm{m}$

(d)

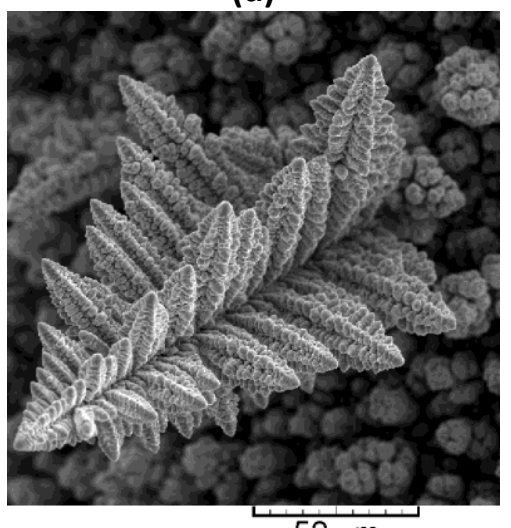

$50 \mu \mathrm{m}$ (b)

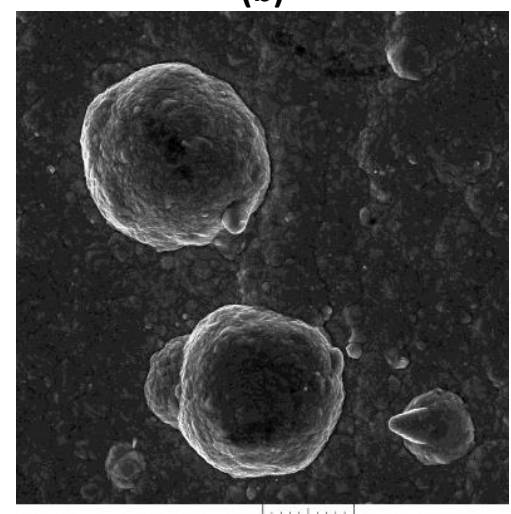

$10 \mu \mathrm{m}$

(e)

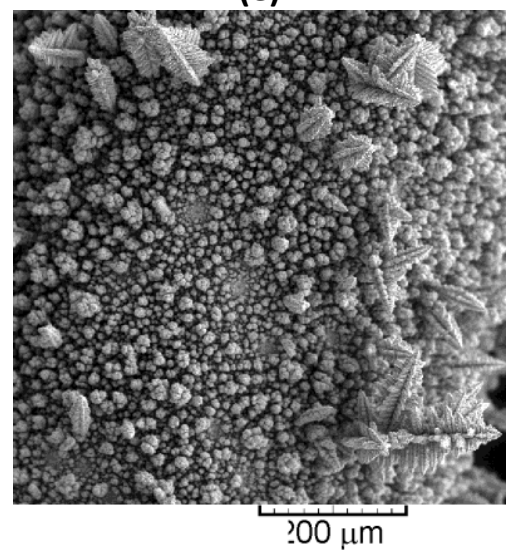

(g) (c)

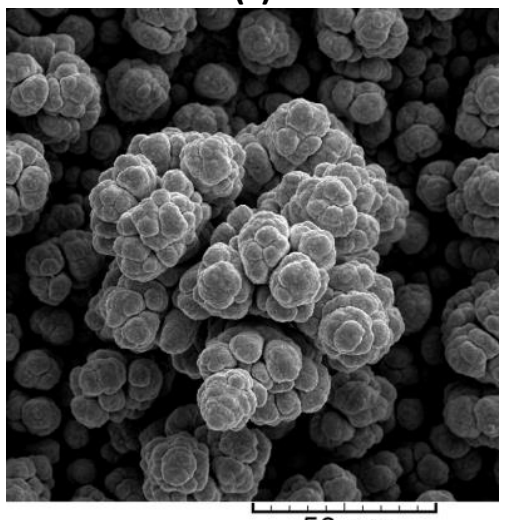

$50 \mu \mathrm{m}$

(f)

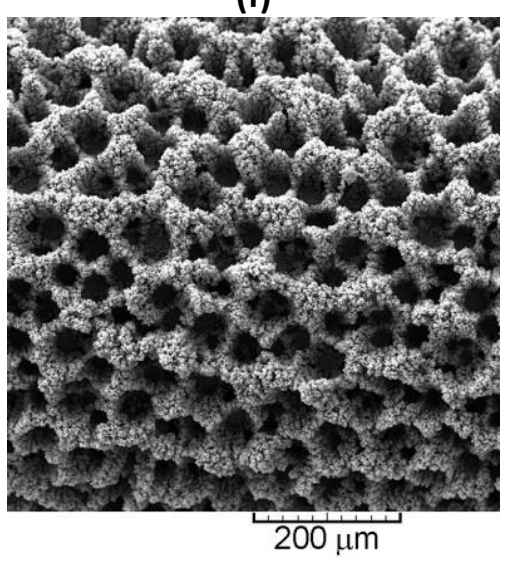

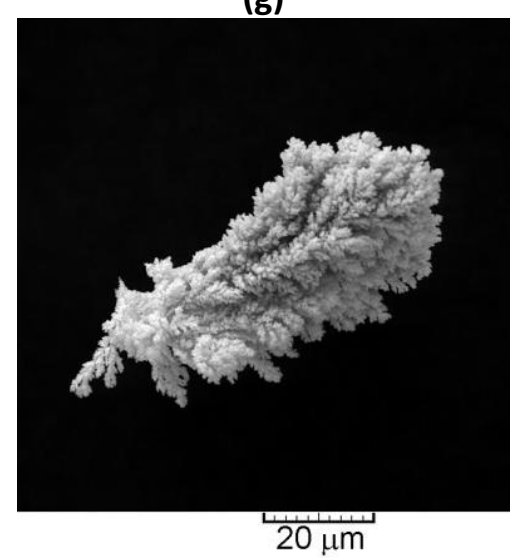

Figure 11. The disperse forms of Cu obtained by electrodeposition from $0.10 \mathrm{M} \mathrm{CuSO}_{4}$ in $0.50 \mathrm{M} \mathrm{H}_{2} \mathrm{SO}_{4}$ : (a) the carrot-like forms $(\eta=210 \mathrm{mV})$ [28], (b) globules $(\eta=210 \mathrm{mV})$ [28], (c) the cauliflower-like forms $(\eta=550 \mathrm{mV})$ [31], (d) the 3D pine-like dendrites $(\eta=625 \mathrm{mV})$ [31], (e) the mixture of the 3D pine-like dendrites, holes and cauliflower-like agglomerates of Cu grains $(\eta=625 \mathrm{mV})$ [31], (f) the honeycomb-like structure $(\eta=1000 \mathrm{mV})[31], \mathrm{g})$ the cauliflower-like particles obtained in the conditions of vigorous hydrogen evolution $(\eta=1000 \mathrm{mV})$ [31].

The amounts of evolved hydrogen during $\mathrm{Cu}$ electrolysis at high overpotentials or current densities are quantified by determination of the average current efficiency of hydrogen evolution $\left(\eta_{1, \text { av }}\left(\mathrm{H}_{2}\right)\right)$, and there is a critical value leading to the change of the hydrodynamic conditions in the 
near-electrode layer. This value is estimated to be about $10.0 \%$ [30]. The values obtained at overpotentials of 625 and $1000 \mathrm{mV}$ were 2.0 and $46.8 \%$, respectively [31], indicating that the value obtained at the overpotential inside the plateau of the limiting diffusion current density was below, while the value obtained at the overpotential outside the plateau of the limiting diffusion current density was above the critical value for the change of hydrodynamic conditions in the near-electrode layer.

In spite of very different macrostructure of the formed disperse forms (dendrites or cauliflowerlike forms), $\mathrm{Cu}$ crystallites were random oriented in the both types of particles [31]. This random orientation can be attributed to the similar micro structure, i.e. to existence of spherical morphology in them. Namely, the both types of disperse forms consisted of small agglomerates of approximately spherical grains at the micro level.

\section{The inert metals}

For this group of metals, there is a parallelism between metal electrodeposition process and hydrogen evolution reaction in the whole range of potentials and current densities. For that reason, it is no possible to record the polarization curve in a classical way, but it is possible with an application of IR drop compensation technique [2,32,33].

\section{Nickel}

The spongy-like particles are formed by $\mathrm{Ni}$ electrodeposition in the powder production range (Fig. 12). The main characteristics of this particle type are holes formed by detached hydrogen bubbles surrounded by cauliflower-like agglomerates of approximately spherical Ni grains. It is clear that this particle type has the honeycomb-like structure.

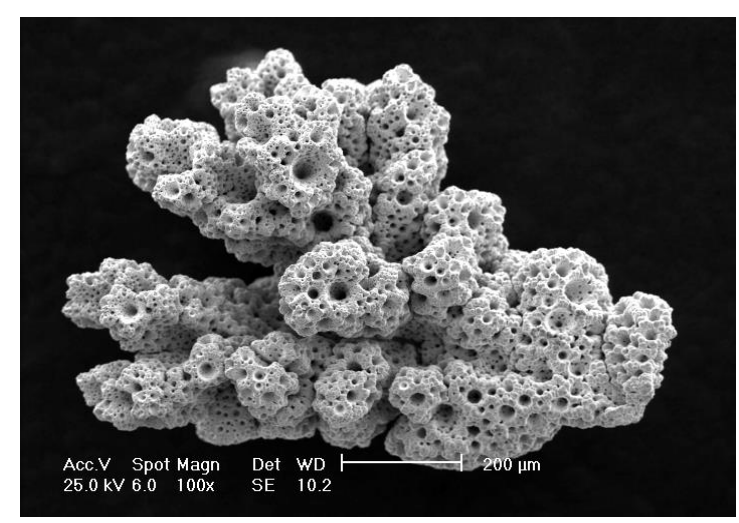

Figure 12. The spongy-like particles of Ni obtained by electrolysis from $0.10 \mathrm{M} \mathrm{NiCl}_{2}+1.0 \mathrm{M} \mathrm{NH}_{4} \mathrm{Cl}+0.70 \mathrm{M} \mathrm{NH}_{4} \mathrm{OH}$ under the condition of limiting diffusion current density [35].

There is no any difference among the spongy-like particles of $\mathrm{Ni}$ formed from various electrolytes $[2,33-36]$, and the spongy-like particles of the other metals from this group, like Co [2,33,37], and Fe $[2,38]$. It is understandable because this particle type is only determined by vigorous hydrogen evolution as a parallel reaction to metal electrolysis in the powder production range.

Crystallites of $\mathrm{Ni}$ were random oriented in the spongy-like particles [36].

\section{Molten salt electrolysis}

The XRD analysis of products of molten salt electrolysis of magnesium nitrate hexahydrate showed that the mixture of $\mathrm{MgO} / \mathrm{Mg}(\mathrm{OH})_{2}$ was formed $[39,40]$. The network of the intertwined needles was formed in the UPD (underpotential) region (Fig. 13a). The holes formed by detached 
hydrogen bubbles and very long needles often grouped into the flower-like aggregates were formed by molten salt electrolysis in the OPD (overpotential) range (Fig. 13b). The hole size decreased, while their number increased with increasing the overpotential of electrodeposition (13c and d).

(a)

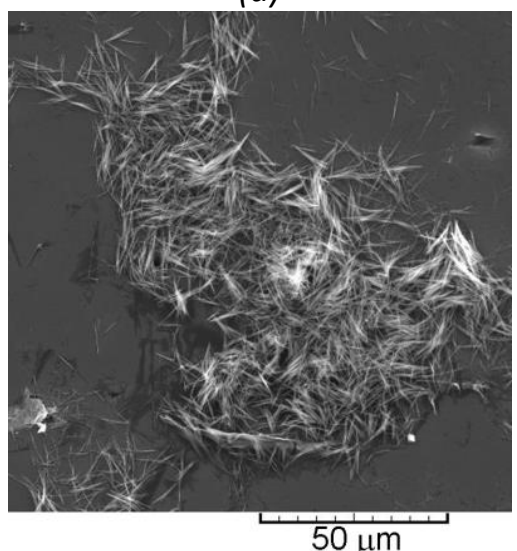

(c)

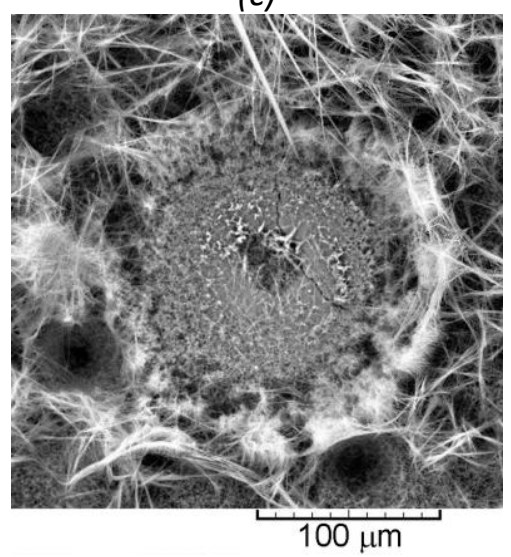

(b)

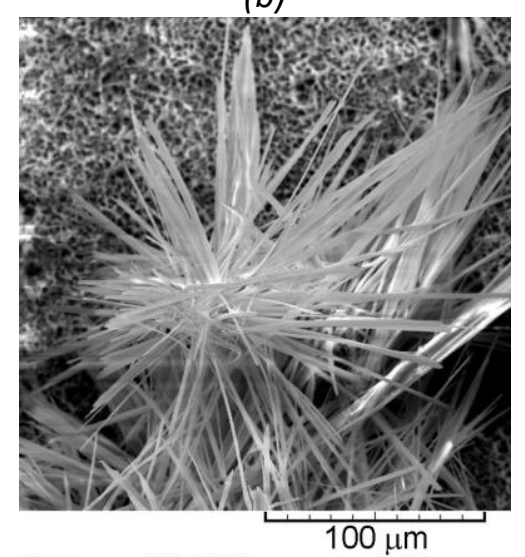

(d)

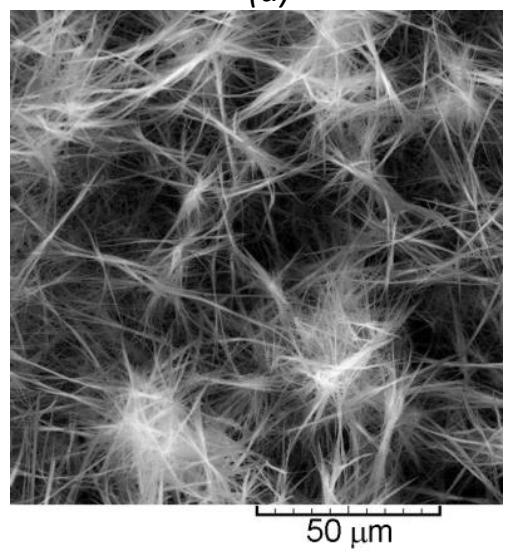

Figure 13. Morphologies of $\mathrm{MgO} / \mathrm{Mg}(\mathrm{OH})_{2}$ deposits: (a) the UPD region; the network of the intertwined needle, (b) the OPD region; very long needles grouped into the flower-like aggregates, (c) the dish-like hole; $\eta=200 \mathrm{mV}$, and (d) holes constructing the honeycomb-like structure; $\eta=1000 \mathrm{mV}$ [39].

\section{General discussion of the presented results}

The polarization curves for $\mathrm{Pb}, \mathrm{Ag}, \mathrm{Zn}$ and $\mathrm{Cu}$ normalized to the limiting diffusion current density values are shown in Fig. 14. Since the plateaus of the limiting diffusion current density at the polarization curves for $\mathrm{Ag}$ from the nitrate electrolyte $(\mathrm{Ag}(\mathrm{NIT}))$ and $\mathrm{Pb}$ are with a slope to the overpotential axis, the values of the current density corresponding to the inflection points are taken as the limiting diffusion current densities. The shape of polarization curves exclusively depends on the type of electrolyte, while only changes in the length of the plateau of the limiting diffusion current density were observed with various concentrations of both the depositing ions and the supporting electrolyte $[6,10,11,27,30]$. As a result of the decrease of the exchange current density (or the rate of electrodeposition), moving of the plateaus of the limiting diffusion current density towards the higher overpotentials of electrodeposition is observed. Simultaneously, the change of shape of a dendrite from the needle-like and the 2D fern-like dendrites to the 3D pine-like dendrites was observed with the decreasing exchange current density values.

The process of complex formation with depositing metal ions lowers the exchange current density value of metal, where the degree of decrease of the exchange current density depends on the strength of formed complex [12,13]. For example, in the case of $\mathrm{Ag}, \mathrm{Ag}$ makes enough strong 
complex with ammonium ions (this electrolyte is denoted with $\operatorname{Ag}(A M)$ in Fig. 14) that a transfer of $\mathrm{Ag}$ from the group of the normal to the group of intermediate metals is enabled.

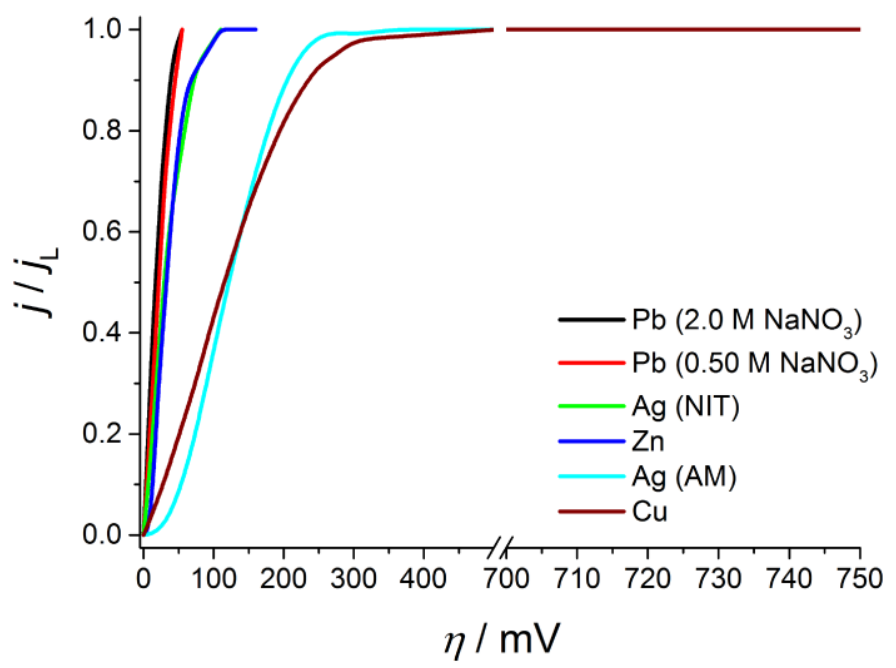

Figure 14. The polarization curves for $\mathrm{Pb}, \mathrm{Ag}, \mathrm{Zn}$ and $\mathrm{Cu}$ normalized to the limiting diffusion current density values

All shown shapes of dendrites follow the electrochemical definition of dendrites. From the electrochemical point of view, a dendrite is defined as an electrode surface protrusion which tip grows under activation control, while electrodeposition to the macroelectrode is predominantly under diffusion control [1,41-45]. This definition follows from an application of the general theory of disperse deposit formation, based on the concept of local diffusion fields formed around the tips and the top edges of surface protrusions formed in the initial stage of electrodeposition and buried deep in the diffusion layer of the macroelectrode. Two types of local diffusion fields are responsible for formation and growth of disperse forms of various shape: (a) spherical - formed around the tips, and (b) cylindrical - formed around the top edges of growing protrusions. According to this theory, the radius of the spherical diffusion layer formed around the tip of the protrusion is equal to radius of the protrusion. During electrodeposition inside the plateau of the limiting diffusion current density, the outer limit of the diffusion layer of the macroelectrode was not disrupted. After the inflection point, the electrodeposition system remains diffusion controlled and the rapid increase in the current density with increasing the overpotential is a result of the fast growth of dendrites and a strong increase of the electrode surface area. Then, using the electrochemical definition of a dendrite, it follows that this sudden and rapid increase of the current density with the increasing overpotential can be mainly ascribed to the activation controlled electrodeposition at the tips of the formed dendrites. It is very clear that the tips of both primary and secondary branches contribute to the overall control of electrodeposition process causing the disruption of the outer limit of the diffusion layer of the macroelectrode.

It is no valid the general theory of disperse deposits formation for formation of the honeycomblike structures. This structure type is formed in the conditions of vigorous hydrogen evolution, and the concept of "effective overpotential" is proposed to explain formation of this structure type [2,29]. According to this concept, when hydrogen evolution is vigorous enough, then electrodeposition process occurs at some overpotential which is effectively lower than the specified one. From morphological point of view, it means that morphologies of metal deposits become similar to those obtained at some lower overpotentials where there is no hydrogen evolution, or it is too small to affect the hydrodynamic conditions in the near-electrode layer. Formation of cauliflower-like 
agglomerates of $\mathrm{Cu}$ grains at the overpotential outside the plateau of the limiting diffusion current density (Fig. 11g) instead of the dendrites formed inside the plateau of the limiting diffusion current density (Fig. 11d) really indicated the lower degree of the diffusion control at the overpotential outside than inside the plateau. In this case, the fast increase in the current density with increasing the overpotential after the end of the plateau of the limiting diffusion current density is a result of vigorous hydrogen evolution.

In spite of vigorous hydrogen evolution accompanied by formation of numerous holes from the detached hydrogen bubbles (the both dish-like holes and those constructing the honeycomb-like structures) [39], formation of very long needles of $\mathrm{MgO} / \mathrm{Mg}(\mathrm{OH})_{2}$ clearly indicates that this molten salt electrolysis process belongs to the very fast electrochemical process.

\section{Conclusions}

The following conclusions concerning formation of disperse forms by electrolysis can be derived:

a) The shape of disperse forms depends on parameters of electrolysis like kind of electrolyte,

b) The shape of disperse forms depends on affiliation to the determined group of metals:

I. normal metals: the needle-like and the 2D fern-like dendrites, crystals of regular and irregular shape, granules, cobweb, mossy, filaments, boulders,

II. intermediate metals: carrot-like and cauliflower-like forms, globules, the 3D pine-like dendrites, and

III. inert metals: the spongy-like particles,

c) The decrease of the exchange current density leads to the change in the shape of dendrites from the needle-like and the 2D fern-like dendrites to the 3D pine-like dendrites, and

d) Vigorous hydrogen evolution changes a mechanism of formation of disperse forms from application of the general theory of disperse deposit formation to application of the concept of "effective overpotential", and

e) The decrease of the exchange current density leads to a change of crystal structure of disperse forms from the strong (111) preferred orientation observed in the needle-like and the 2D fernlike dendrites to almost randomly oriented metal crystallites in the 3D pine-like dendrites, the spongy-like and the cauliflower-like particles.

Acknowledgements: This work was supported by the Ministry of Education, Science, and Technological Development of the Republic of Serbia under the research project: "Electrochemical synthesis and characterization of nanostructured functional materials for application in new technologies" (project no. 172046).

\section{References}

[1] K. I. Popov, S. S. Djokić, B. N. Grgur, Fundamental aspects of electrometallurgy, New York, Kluwer Academic/Plenum Publishers, New York, USA, 2002, p.p. 1-305.

[2] K. I.Popov, S. S.Djokić, N. D.Nikolić, V. D. Jović, Morphology of Electrochemically and Chemically Deposited Metals, Springer, Switzerland, 2016, p.p. 1-368.

[3] R. Winand, Electrochimica Acta 39 (1994) 1091-1105.

[4] N. D. Nikolić, P.M. Živković, G. Branković, M.G. Pavlović, Journal of the Serbian Chemical Society 82 (2017) 539-550.

[5] K. Fetter, Electrochemical Kinetics, Moscow, Khimiya, 1967 (in Russian).

[6] N. D. Nikolić, P. M. Živković, J. D. Lović, G. Branković, Journal of Electroanalytical Chemistry 785 (2017) 65-74.

[7] J. O'M. Bockris, Z. Nagy, A. Damjanović, Journal of The Electrochemical Society 119 (1972) 285-295.

[8] K. I. Popov, N .V. Krstajić, S. R. Popov, Surface Technology 20 (1983) 203-208. 
[9] K .I. Popov, B. N. Grgur, E. R. Stojilković, M. G. Pavlović, N. D. Nikolić, Journal of the Serbian Chemical Society 62 (1997) 433-442.

[10] N. D. Nikolić, K. I. Popov, P. M. Živković, G. Branković, Journal of Electroanalytical Chemistry 691 (2013) 66-76.

[11] N. D. Nikolić, P. M. Živković, S. I. Stevanović, G. Branković, Journal of the Serbian Chemical Society 81 (2016) 553-566.

[12] N. D. Nikolić, Dj. Dj. Vaštag, P. M. Živković, B. Jokić, G. Branković, Advanced Powder Technology 24 (2013) 674-682.

[13] N. D. Nikolić, Dj. Dj. Vaštag, V. M. Maksimović, G. Branković, Transactions of Nonferrous Metals Society of China 24 (2014) 884-892.

[14] N. D. Nikolić, K. I. Popov, A New Approach to the Understanding of the Mechanism of Lead Electrodeposition, in Electrodeposition and Surface Finishing, Series: Modern Aspects of Electrochemistry, S.S. Djokić, Ed., vol. 57, Springer, 2014, pp. 85 - 132.

[15] G. Wranglen, Electrochimica Acta 2 (1960) 130-146.

[16] H. M. Liaw, J. W. Faust Jr, Journal of Crystal Growth 18 (1973) 250-256.

[17] N. D. Nikolić, E. R. Ivanović, G. Branković, U. Č. Lačnjevac, S. I. Stevanović, J. S. Stevanović, M. G. Pavlović, Metallurgical and Materials Transactions. B: Process Metallurgy and Materials 46 (2015) 1760-1774.

[18] N. D. Nikolić, S. I. Stevanović, G. Branković, Transactions of Nonferrous Metals Society of China 26 (2016) 3274-3282.

[19] N. D. Nikolić, V. M. Maksimović, G. Branković, RSC Advances 3 (2013) 7466-7471.

[20] N. D. Nikolić, V. M. Maksimović, G. Branković, P. M. Živković, M. G. Pavlović, Journal of the Serbian Chemical Society 78 (2013) 1387-1395.

[21] R. Sivasubramanian, M. V. Sangaranarayanan, CrystEngComm 15 (2013) 2052-2056.

[22] Y. Xia, Y. Xiong, B. Lim, S. E. Skrabalak, Angewandte Chemie International Edition 48 (2009) 60-103.

[23] J. O`M. Bockris, A. K. N. Reddy, M. Gamboa-Aldeco, Modern Electrochemistry 2A, Fundamentals of Electrodics, Kluwer Academic/Plenum Publishers, New York, USA, 2000, p. 1333.

[24] Lj. Avramović, E. R. Ivanović, V. M. Maksimović, M. M. Pavlović, M. Vuković, J. S. Stevanović, N. D. Nikolić, Transactions of Nonferrous Metals Society of China 28 (2018) 1903-1912.

[25] Lj. Avramović, M. Bugarin, D. Milanović, V. Conić, M. M. Pavlović, M. Vuković, N. D. Nikolić, Journal of Mining and Metallurgy, Section B: Metallurgy 54 B (2018) 291-300.

[26] N. D. Nikolić, P. M. Živković, B. Jokić, M. G. Pavlović, J. S. Stevanović, Macedonian Journal of Chemistry and Chemical Engineering 33 (2014) 169-180.

[27] N. D. Nikolić, G. Branković, M. G. Pavlović, K. I. Popov, Journal of Electroanalytical Chemistry 621 (2008) 13-21.

[28] K. I. Popov, P. M. Živković, B. Jokić, N. D. Nikolić, Journal of the Serbian Chemical Society 81 (2016) 291-306.

[29] N. D. Nikolić, K. I. Popov, Lj. J. Pavlović, M. G. Pavlović, Journal of Electroanalytical Chemistry 588 (2006) 88-98.

[30] N. D. Nikolić, K. I. Popov, Lj. J. Pavlović, M. G. Pavlović, Sensors 7 (2007) 1-15.

[31] N. D. Nikolić, Lj. Avramović, E. R. Ivanović, V. M. Maksimović, Z. Baščarević, N. Ignjatović, Transactions of Nonferrous Metals Society of China 29 (2019) 1275-1284.

[32] V. D. Jović, B. M. Jović, M. G. Pavlović, Electrochimica Acta 51 (2006) 5468-5477.

[33] V. D. Jović, N. D. Nikolić, U. Č. Lačnjevac, B. M. Jović, K. I. Popov, Morphology of Different Electrodeposited Pure Metal Powders, in Electrochemical Production of Metal Powders, Series: Modern Aspects of Electrochemistry, S.S. Djokić, Ed., vol. 54. Springer, New York, USA, 2012, p.p. 63-123.

[34] V. D. Jović, V. M. Maksimović, M. G. Pavlović, K. I. Popov, Journal of Solid State Electrochemistry 10 (2006) 373-379.

[35] V. D. Jović, B. M. Jović, V. Maksimović, M. G. Pavlović, Electrochimica Acta 52 (2007) 4254-4263.

[36] N. D. Nikolić, V. M. Maksimović, G. Branković, P. M. Živković, M. G. Pavlović, Materials Protection 59 (2018) 256-264.

[37] V. M. Maksimović, N. D. Nikolić, V. B. Kusigerski, J. L. Blanuša, Journal of the Serbian Chemical Society 80 (2015) 197-207. 
[38] Lj. J. Pavlović, M. M. Pavlović, M. G. Pavlović, N. D. Nikolić, M. V. Tomić, International Journal of Electrochemical Science 5 (2010) 1898-1910.

[39] V. S . Cvetković, N. M. Vukićević, N.D . Nikolić, G. Branković, T. S. Barudžija, J. N . Jovićević, Electrochimica Acta 268 (2018) 494-502.

[40] V.S . Cvetković, N. M. Vukićević, N. D. Nikolić, Z. Baščarević, T. S. Barudžija, J. N. Jovićević, Journal of Electroanalytical Chemistry 842 (2019) 168-175.

[41] K. I. Popov, N. V. Krstajić, M. I. Čekerevac, The mechanism of formation of coarse and disperse electrodeposits, in Modern Aspects of Electrochemistry, R. E. White, B. E. Conway, J. O'M. Bockris, Eds., vol. 30, Plenum Press, New York, USA, 1996, p.p. 261-312.

[42] A. R. Despić, K. I. Popov, Transport controlled deposition and dissolution of metals, in Modern Aspects of Electrochemistry, B. E. Conway, J. O’M. Bockris, Eds., vol. 7, Plenum Press, New York, USA, 1972, p.p. 199-313.

[43] J. W. Diggle, A. R. Despić, J. O`M. Bockris, Journal of The Electrochemical Society 116 (1969) 15031514.

[44] K. I. Popov, N. D. Nikolić, General Theory of Disperse Metal Electrodeposits Formation, in Electrochemical Production of Metal Powders, Series: Modern Aspects of Electrochemistry, S.S. Djokić, Ed., vol. 54, Springer, 2012, p.p. 1-62.

[45] N. D. Nikolić, K. I. Popov, E. R. Ivanović, G. Branković, S. I. Stevanović, P. M. Živković, Journal of Electroanalytical Chemistry 739 (2015) 137-148.

(C2019 by the authors; licensee IAPC, Zagreb, Croatia. This article is an open-access article distributed under the terms and conditions of the Creative Commons Attribution license (http://creativecommons. org/licenses/by/4.0/) 